\title{
Role of Argyrophilic Nucleolar Organizer Region (AgNOR) Study in Cytological Evaluation of Serous Fluids for Detection of Malignancy
}

\author{
Abhinav Junwal' ${ }^{1}$, Reeni Malik², Sharda Balani' ${ }^{3}$, Ravi Kumar Meena ${ }^{4}$, Seema Jathapi ${ }^{5}$ \\ 1, 2,3, 4, 5 Department of Pathology, Gandhi Medical College, Bhopal, Madhya Pradesh, India.
}

\section{ABSTRACT}

\section{BACKGROUND}

Malignant tumours cause effusion by direct involvement of serous membranes by tumour invasion, or by secondary inflammatory reaction causing serous effusions. Identification of tumour cells in serous fluids is often difficult by regular cytology. Nucleolar Organizer Regions (NORs) are loops of DNA situated in acrocentric chromosomes. These NORs are evaluated by silver staining technique that recognizes these argyrophilic proteins which are bigger and are more dispersed in malignancies.

\section{METHODS}

A total of 97 serous effusions received at the Department of Pathology, GMC, Bhopal were included in the study. Smears were studied by conventional Papanicolaou and haematoxylin and eosin stains. Variation of AgNOR dots in smears were graded and compared in malignant and non-malignant effusions.

\section{RESULTS}

AgNOR dispersion up to $1+$ was observed in maximum patients with reactive mesothelial cells whereas AgNOR dispersion of $3+$ was observed in $80 \%$ patients with malignant cells. Similarly, AgNOR size was up to $1+$ in maximum cases with reactive mesothelial cells whereas it was $3+$ in $70 \%$ cases with malignant cells. The present study observed statistically significant association of AgNOR dispersion and size with malignant as well as reactive mesothelial cells $(p<0.01)$.

\section{CONCLUSIONS}

The study of AgNOR size and dispersion was found to be clinically useful as an ancillary diagnostic tool for use in serous effusion when the cytologic diagnosis is ambiguous.

\section{KEY WORDS}

AgNOR Staining, Benign and Malignant Effusions
Corresponding Author:

Dr. Sharda Balani

A - 68, Vijay Nagar, Lalghati,

Bhopal, Madhya Pradesh,

India.

E-mail:dr.shardabalani@gmail.com

DOI: $10.14260 / j e m d s / 2020 / 759$

How to Cite This Article:

Junwal A, Malik R, Balani S, et al. The role of argyrophilic nucleolar organizer region (AgNOR) study in cytological evaluation of serous fluids for detection of malignancy. J Evolution Med Dent Sci 2020;9(46): 34693473, DOI: 10.14260/jemds/2020/759

Submission 27-07-2020,

Peer Review 02-10-2020,

Acceptance 07-10-2020,

Published 16-11-2020.

Copyright (C) 2020 Abhinav Junwal et al. This is an open access article distributed under Creative Commons Attribution License [Attribution 4.0 International (CC BY 4.0)] 


\section{BACKGROUND}

Serous effusions are accumulated fluids within the body cavities, that is, pleural, pericardial, and peritoneal. A variety of conditions ranging from inflammatory to neoplastic, are responsible for the occurrence of these effusions. Malignant tumours cause effusion by direct involvement of serous membranes by tumour invasion or by secondary inflammatory reaction. ${ }^{1}$

A variety of conditions ranging from inflammatory to neoplastic, cause these effusions. Malignant tumours cause effusion by direct involvement of serous membranes by tumour invasion or by secondary inflammatory reaction. ${ }^{2}$ Detection of malignant cells in effusion is important for clinical staging of tumour and deciding the line of treatment. An accurate identification of tumour cells in pleural and peritoneal fluids is often difficult. Sensitivity of conventional cytology for the identification of malignant cells varies from 50 - $78 \%{ }^{3}$ Histochemical stains, electron microscopy and immunocytochemical studies can aid cytological evaluation of effusions for getting a definitive diagnosis, but such methods are time consuming and costly, and some antigens suitable for this purpose are expressed by normal as well as reactively proliferated mesothelial cells. ${ }^{4}$

Silver staining for Argyrophilic Nucleolar Organizer Regions (AgNOR) has been found to be useful in making a cytopathologic diagnosis of malignant cells in serous effusions. Nucleolar Organizer Regions (NORs) are loops of DNA located in acrocentric chromosomes. These NORs are seen and examined by silver staining technique that recognizes these argyrophilia associated proteins which are increased in malignancy. ${ }^{3}$ It is a less expensive and equally efficient method for differentiating reactive and malignant effusions. ${ }^{1}$ AgNOR staining is a technique to detect the argyrophilia of the nucleolar organizer regions related proteins. NORs are loops of ribosomal DNA responsible for the transcription of ribosomal RNA on the short arm of acrocentric human chromosomes and thus play an important role in protein synthesis. ${ }^{5}$ Two argyrophilic proteins are nucleolin and nucleophosmin. ${ }^{6}$ These argyrophilic proteins are stained by silver stains after which they can be identified as black dots present throughout the nucleolar area. The number of detectable NORs and AgNORs depends on several factors; the level of transcriptional activity, the number of NOR bearing chromosomes in the karyotype and stage of the cell cycle in which they are sought. The number and size of the NORs reflect cell activity and are related to cell ploidy, proliferative activity or rate of transcription. NORs are important in protein synthesis and the formation of the nucleolus. The abundance and intensity of AgNOR are an indicator of not only their absolute number and dispersion but also their transcriptional activity. It is probable that residual AgNOR protein persist even after transcriptional activity has ceased. The frequency of AgNORs within the nuclei is higher in malignant cells than in normal, reactive or benign neoplastic cells. ${ }^{7}$ In a rapidly proliferating cell, the chromosomal and AgNOR distribution remains disorganized with the resultant formation of multiple, small and dispersed nucleoli.

In the present study we applied the AgNOR silver staining technique to aspirated samples of benign and malignant effusions to evaluate its potential to distinguish malignant cells from benign and reactive ones.

\section{METHODS}

This study was conducted as a cross sectional study in the Cytopathology Lab, Department of Pathology, Gandhi Medical College, Bhopal, during the period of January 2018 to June 2019. All serous effusion samples for malignant cytology (peritoneal, pleural and pericardial) received in for cytological examination were included. Selection of cases was retrospective from March 2017 to May 2018 and the prospective from June 2018 to June 2019 were included in the study. In ward patients from various departments with effusions suspicious of malignancy were selected. A total number of 97 cases were selected of which 55 were peritoneal, 39 were pleural and 3 were pericardial effusions.

The effusions were centrifuged at a speed of $2000 \mathrm{rpm}$ for 5 minutes. Smear were prepared from sediment for AgNOR staining and quickly immersed in $95 \%$ ethanol before drying. AgNOR staining solution was prepared by dissolving $2 \mathrm{~g}$ of gelatin in $1 \%$ aqueous formic acid to make $100 \mathrm{ml}$ solution at a concentration of $2 \%$ (solution A). Fifty percent aqueous silver nitrate solution was prepared by dissolving $5 \mathrm{~g}$ of silver nitrate in triple distilled water to make $10 \mathrm{ml}$ solution (solution B). Working solution was prepared by mixing solution $A$ and $B$ in a proportion of 1:2 volumes and poured over the smears immediately after preparation and left for 60 minutes at room temperature. The silver colloid formed was washed off with triple distilled water and the smears were counterstained with neutral red $1.0 \%$. Smears were washed with triple distilled water and dehydrated through ascending grades of alcohol, cleared with xylene and mounted in DPX. When extra unstained smear were not available, silver staining was done on Pap or Giemsa stained smears after destaining. AgNORs were counted using $\times 100$ oil immersion objective as black dots in the nuclei of all cells. The pattern of AgNOR dispersion and their shape was compared in reactive and malignant cases. The size variation and distribution of AgNORs were performed by the following criteria used by Ahsan et al. ${ }^{8}$

Distribution of AgNORs in the nuclei was graded as ${ }^{8}$

$0=$ Limited to the nucleoli

$1+=$ Occasional dispersion outside nucleoli

$2+=$ Moderate dispersion outside nucleoli

$3+=$ Widely dispersed throughout the nucleus

Size variation of AgNORs was graded as ${ }^{8}$

$0=$ More or less uniform in size

$1+=$ Two different sizes

$2+=$ More than two different sizes

$3+=$ All grades and sizes including too minute to be counted

\section{Statistical Analysis}

Data was collected and entered in Microsoft Excel 2007 sheet. Statistical analysis and cross tabulations were done using SPSS software version 16 . Chi square test was applied to assess the association of AgNOR size and dispersion with mesothelial cells. $\mathrm{P}$ value less than 0.05 was considered statistically significant. Sensitivity, specificity, POV and NPV was calculated for AgNOR size and dispersion and expressed as percentage. 


\section{RESULTS}

97 cases of serous effusions were observed. The mean age of patients was $43.02 \pm 15.96$ years (range 12 - 85 years). Majority of patients belonged to 21 to 40 years of age group (44.3\%) followed by $32 \%$ belonging to age group of 41 to 60 years, amongst which $51.5 \%$ were females and $48.5 \%$ were males. The most common site was peritoneal in 55 (56.7\%) patients followed by pleural and pericardial in $40.2 \%$ and 3.1 $\%$ patients respectively.

Association between AgNOR dispersion and nature of cells - AgNOR dispersion up to 1 + was observed in maximum patients with reactive mesothelial cells whereas AgNOR dispersion of $3+$ was observed in $80 \%$ patients with malignant cells. The present study observed statistically highly significant association of AgNOR dispersion with malignant as well as reactive mesothelial cells $(p<0.01)$. (Table 1$)$
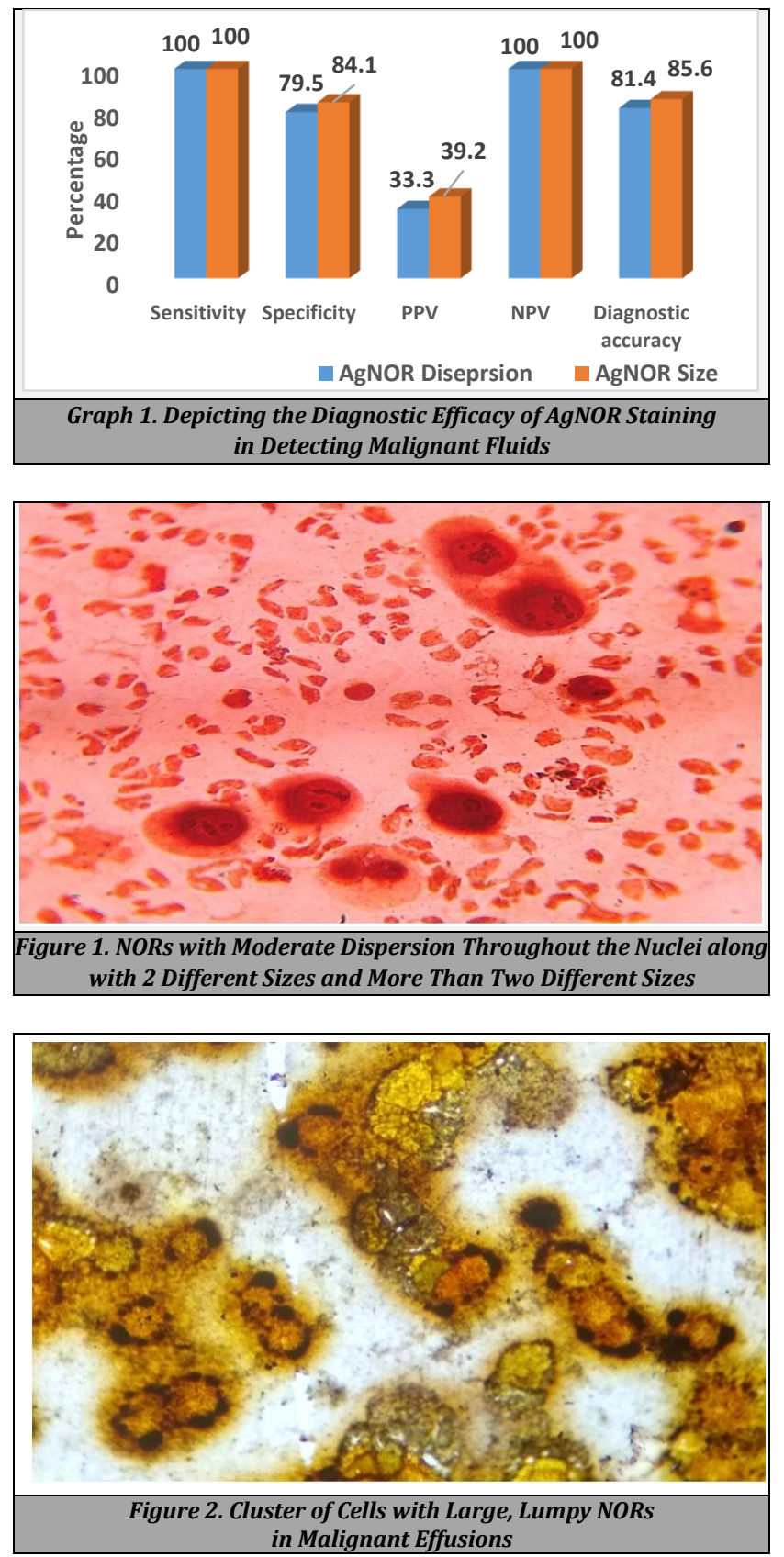

\section{DISCUSSION}

The study was conducted on a total of 97 malignant or reactive-pleural, pericardial and peritoneal effusions which were investigated for malignant cytology. Serous effusions may occur due to variety of abnormalities and insults in patients without cancer and the cellular response is nonspecific in vast majority of the cases. However, the most significant role of cytopathology is in the examination of effusion fluid for the presence of cancer cells. ${ }^{9,10}$ Silver staining for argyrophilic nucleolar organizer region has been found useful in making a cytopathologic diagnosis between benign, reactive and malignant cells. Nucleolar organizer regions are loops of DNA situated in acrocentric chromosomes. These NORs are visualized by silver staining technique that recognizes these argyrophilia associated proteins which are increased in malignancy. ${ }^{3}$

In the study the mean age was $43.02 \pm 15.96$ years (range12 - 85 years) and maximum patients belonged to 21 to 40 years of age group (44.3\%), the mean age was lower in comparison to study done by Palathingal MR et al in which it was 60.32 years and frequent age group being $41-60$ years (50\%). ${ }^{11}$ Karki $\mathrm{S}$ et al in their study included 174 cases, of whom 103 (59.2\%) peritoneal and 71 (40.8\%) pleural fluids were collected. The age ranged from 1 - 95 years (mean - 48.3) in patients from whom peritoneal fluid was collected whereas the age ranged from 1 - 88 years (mean - 52.7) from whom pleural fluid was collected. ${ }^{3}$

Torabi Nehzad S et al studied cytomorphologically 32 (34 \%) normal cases, 28 (29.8\%) reactive and 34 (36.2\%) malignant cases with the mean age of $40.78,54.07$ and 54.87 years respectively. 12

Fagere MOM et al in their study concluded that peritoneal effusions were more likely to be malignant (91\%) than pleural effusions which was concordant to our study. ${ }^{13}$

Dispersion of AgNORs were observed and classified as 0, 1 ,$+ 2+$ and $3+$ based upon dispersion limited to nucleoli or dispersion away from nucleoli. The farther the dispersion away from nucleoli, the chances of malignancy are high. AgNOR dispersion up to $1+$ was observed in maximum patients (59.1\%) with reactive mesothelial cells whereas AgNOR dispersion of $3+$ was observed in $80 \%$ patients with malignant cells and the observed association of AgNOR dispersion with malignant as well as reactive mesothelial cells were highly statistically significant $(p<0.01)$. The number of visible AgNORs in a nucleus reflects the phase of transcription of cells thus the nuclei of malignant cells contains AgNORs in significantly elevated numbers and sizes than to normal, reactive or benign neoplastic cells. ${ }^{14,15}$ Palathingal MR et al in their study the AgNOR black dots were more irregularly distributed in malignant effusions compared to reactive or normal mesothelial cells. ${ }^{11}$ The findings of present study were also similar to study by Ibnerasa SN et al in which the authors reported a highly significant difference ( $\mathrm{p}<0.001)$. In distribution of AgNORs between benign and malignant effusions. ${ }^{16}$ AgNOR distribution was irregular and had a grade of $2+$ to $3+$ in the majority of the malignant effusions in a study by Karki $S$ et al ${ }^{3}$ Akhtar GN et al studied dispersion in effusions and reported that AgNORs were less dispersed in nonmalignant than in malignant effusions. ${ }^{17}$ 
Size of AgNORs were classified based upon their uniformity. Cells of malignant type are classified as heterogeneous as per AgNOR. The present study reported AgNOR size of upto $1+$ in maximum cases (68.2 \%) with reactive mesothelial cells whereas it was $3+$ in $70 \%$ cases with malignant cells and the observed association was statistically highly significant $(\mathrm{p}<0.01)$. The findings of present study were in concordance to the study by Palathingal MR et al. The author concluded AgNORs were more homogenous in size and graded as 0 and $1+$ in reactive effusions, while in malignant effusions AgNORs were heterogenous with grades of $2+$ and 3 .$+{ }^{11} \mathrm{Gill} \mathrm{M}$ et al also documented similar findings. They noted a differentiation between activated mesothelial cells and malignant cells based on AgNORs. The benign group consisted of AgNORs showing 1 to 2 dots of regular size and shape whereas AgNORs in malignant group, 3 to 5 dots of variable size, shape and irregular contours were observed per cell. In atypical group, the reactive mesothelial cells showed 1 to 2 dots, malignant cells showed 3 to 4 irregular dots. ${ }^{18}$

Assessment of AgNORs have proved and explained the importance of the size and nucleus distribution in cases of malignant as well as other effusions. According to the criteria proposed by Ahsan, the present study observed higher dispersion and heterogenous size of AgNORs. Out of 43 patients with reactive effusion, AgNOR dispersion of $1+$ was observed in $51.2 \%$ patients whereas AgNOR dispersion of 3+ was observed in $88.9 \%$ cases with malignant effusion. Similarly size of AgNORs were $1+$ in $44.2 \%$ cases of reactive effusions whereas malignant effusions were characterized by more heterogeneous size $(3+)$. Thus greater dispersion and heterogenicity was observed in cases of malignant effusions $s$ ( $p<0.01$ ). Our findings were in accordance to study by Karki $S$ et al in which AgNORs were heterogeneous in size and graded $2+$ to $3+$ in most malignant cases whereas, they were uniform in size in cases of non-malignant effusions and graded 0 to $1+.3$ The findings of present study were also supported by Palathingal MR et al in which the authors documented AgNORs were less dispersed and more uniform in reactive effusions than in malignant effusion. ${ }^{11}$

Changes in AgNOR size and number are primarily the result of differences in the activation status of rDNA due to increased cell proliferation. ${ }^{19}$ Various literature have demonstrated that silver-staining methods selectively stain acidic proteins (AgNOR proteins) associated with the ribosomal sequences. Thus, silver staining for AgNOR proteins to interphase nuclei showed the localization of the ribosomal genes in the fibrillar components of the nucleolus (fibrillary centres and dense fibrillary component) which thus represent the interphase counterpart of metaphase NORs. It is a known fact that malignant cells have hypertrophic and irregular shaped nucleoli along with irregular distribution of the nucleolar components. These morphologic abnormalities can be quantified using the distribution of interphase NORs in nucleoli as a parameter. 20,21

Cytological diagnosis classified malignant effusions in 9 out of 97 cases. Diagnostic efficacy of AgNOR size and dispersion was calculated separately in present study against the cytological diagnosis. AgNORs dispersion and size 0 to $1+$ were classified as normal whereas AgNORs dispersion and size between $2+$ to $3+$ were classified as pointing towards malignancy. The sensitivity and NPV based upon AgNOR dispersion and size was calculated as $100 \%$ whereas specificity was $84.1 \%$ based upon AgNOR size and $79.5 \%$ for AgNOR dispersion. Both the tests i.e. dispersion and size were observed to have low positive predictive value. To our knowledge, diagnostic accuracy have been calculated based upon AgNOR count, this study is unique to assess the diagnostic accuracy based on size and dispersion. The outcome of present study reflect the importance of AgNORs size and nucleus distribution in diagnosis of malignant cells.

Palathingal MR et al demonstrated the diagnostic accuracy based on AgNOR count. The sensitivity and specificity of the test at mean AgNOR value. The sensitivity in the reference study was observed to be decreasing with the increase in mean AgNOR count, but specificity and positive predictive value increased with the mean AgNOR count. At a value of 2.57 both these values were around $100 \%{ }^{11}$ Karki S et al in their study reported high AgNOR count and higher size and dispersion as well as high proliferative index in 9 out of the 10 cytologically diagnosed suspicious cases of malignancy. Thus they concluded AgNOR as a useful technique is detecting malignant cells in effusions. ${ }^{3}$ Torabi Nehzad $S$ et al concluded that AgNOR method is a specific diagnostic tool for serosal cavity effusions, especially when malignancy is suspected. ${ }^{12}$ Thus, AgNOR can be regarded as an extremely useful additional diagnostic tool for cytodiagnosis of serous effusions.

\section{CONCLUSIONS}

AgNORs in malignant cells are large, widely and irregularly distributed throughout the nucleus and are heterogeneous in size. Reactive mesothelial cells are characterized by minimally dispersed, homogenously sized, regularly clustered AgNORs. AgNORs were also seen in inflammatory smears with minimal dispersion and mostly single dots with no size variation. This study is unique as it assesses the diagnostic accuracy just based on the basis of AgNOR size and dispersion. In cases where cytology fails to give a definitive diagnosis regarding malignant effusions, it becomes difficult for the clinician to approach and decide the line of treatment. In such cases, AgNOR studies will be very useful, significant and most importantly very economical technique to reach, check and confirm the cytopathological diagnosis.

Data sharing statement provided by the authors is available with the full text of this article at jemds.com.

Financial or other competing interests: None.

Disclosure forms provided by the authors are available with the full text of this article at jemds.com.

\section{REFERENCES}

[1] Ganjei-Azar P, Jorda M, Krishan A. Effusion cytology: a practical guide to cancer diagnosis. Demos Medical Publishing 2010.

[2] Takahashi M. Effusions in body cavities. Color atlas of cancer cytology. Tokyo: Igaku Shoin 2000.

[3] Karki S, Jha A, Sayami G. The role of argyrophilic nucleolar organizer region (AgNOR) study in cytological evaluation of fluids, especially for detection of malignancy. Kathmandu University Medical Journal 2012;10(1):3439. 
[4] Mezger J, Stotzer 0, Schilli G, et al. Identification of carcinoma cells in ascitic and pleural fluid. Comparison of four panepithelial antigens with carcinoembryonic antigen. Acta Cytol 1992;36(1):75-81.

[5] Ferguson-Smith MA, Handmaker SD. Observations on the satellited human chromosomes. Lancet 1961;1(7178):638-40.

[6] Derenzini M. The AgNORs. Micron 2000;31(2):117-20.

[7] Rocher A, Blanco AM, Palaoro L. Usefulness of AgNOR technique in the interpretation of serous effusions. Rev Med Chil 2000;128(9):963-8.

[8] Ahsan S, Tayyab M, Chaudhry NA, et al. Silver staining nucleolar organizer region (AgNOR) typing in nodular hyperplasia of the prostate. Pak Postgraduate Med J 1992;2(3):67-72.

[9] Murphy WM, Ng ABP. Determination of primary site by examination of cancer cells in body fluids. American Journal of Clinical Pathology 1972;58(5):479-88.

[10] Spriggs AI, Boddington MM. The cytology of effusions. New York: Grune \& Stratton Inc 1968.

[11] Palathingal MR, Rose F, Prasad PH. Role of argyrophilic nucleolar organiser region staining in effusions for detection of malignancy - diagnostic test evaluation. JMSCR 2017;5(9):27778-84.

[12] Torabi-Nezhad S, Azarian A. Differentiation between benign, reactive and malignant cells in serosal body fluids by AgNOR staining. Medical Journal of The Islamic Republic of Iran (MJIRI). 2002;16(2):95-100.
[13] Fagere MOM. Diagnostic utility of AgNORs staining of serous effusion among sudanese patients. International Journal of Science and Technology 2016;5(1):36-42.

[14] Crocker J, Skilbeck N. Nucleolar organiser region associated proteins in cutaneous melanotic lesions: a quantitative study. J Clin Pathol 1987;40(8):885-9.

[15] Derenzini M, Betts CM, Eusebi V. Distribution of interphase nucleolar organiser regions and diagnosis of malignancy. Lancet 1987;2(8553):286.

[16] Ibnerasa SN, Chaudhry NA, Khan SA. AgNOR proliferative index in malignant pleural and peritoneal effusions. International Journal of Pathology 2005;3(2):86-90.

[17] Akhtar GN, Ahmed CN, Muhammad T, et al. AgNOR staining in malignant and benign effusions. Pakistan Journal of Medical Sciences 2004;20(1):29-32.

[18] Gill M, Singh U, Mahapatra QS, et al. Role of argyrophilic nucleolar organizer region staining in identification of malignant cells in effusion. J Cytol 2011;28(4):191-5.

[19] Goessens G. Nucleolar structure. In: International review of cytology. Academic Press 1984;87:107-58.

[20] Howell WM. Selective staining of nucleolus organizer regions (NORs). Cell Nucleus 1982;11:89-142.

[21] Zatsepina O, Hozak P, Babadjanyan D, et al. Quantitative ultrastructural study of nucleolus-organizing regions at some stages of the cell cycle (G0 period, G2 period, mitosis). Biology of the Cell 1988;62(3):211-8. 